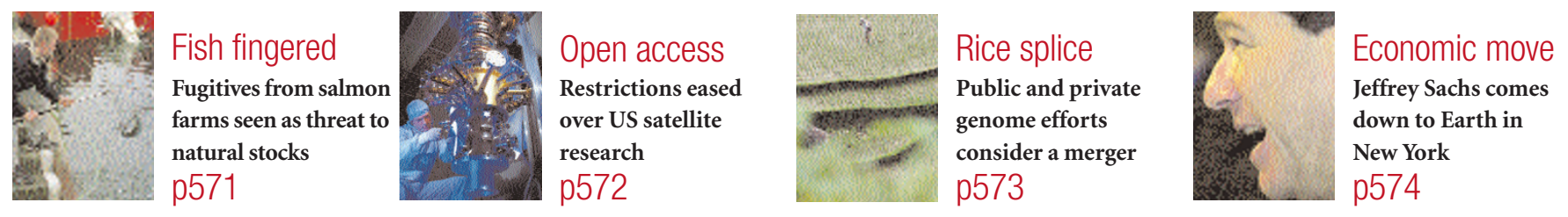

\title{
Ranches blamed over spread of mad deer
}

Jonathan Knight, San Francisco

A relative of mad cow disease that afflicts elk and deer appears to be defying efforts to stop its spread across North America.

Some wildlife officials suspect the proliferation of elk and deer ranches is partly to blame for the recent appearance of the disease in new locations in the United States and Canada. Others fear that wild populations in more places than had previously been realized may be harbouring the disease .

Chronic wasting disease (CWD) - a transmissible spongiform encephalopathy, like mad cow disease and the human form Creutzfeldt-Jakob disease - has been endemic among wild populations of deer and elk in areas near where the borders of Colorado, Wyoming and Nebraska meet, at least since the 1960s, when the first cases were discovered.

Although there is no evidence that CWD has been transmitted to either humans or cattle, wildlife agencies are watching the spread of the disease with some trepidation, given the public alarm that any such transmission would generate.

In 1996, CWD was found on an elk ranch in Saskatchewan in Canada, and since then the disease has turned up on more than a dozen ranches as far south as Oklahoma. All the infected herds have been destroyed, along with herds on farms identified as having received elk from them. Last October, after the disease appeared in herds belonging to one of the largest suppliers of elk in Colorado, the US Department of Agriculture authorized \$2.6 million in emergency spending to keep the disease under surveillance and to compensate affected ranchers.

But in February, routine screening of white-tail deer killed by hunters turned up three infected animals in central Wisconsin, 800 miles east of the closest previously known case. Wildlife officials immediately began culling 500 more deer from the area for testing. By 5 April, nine more cases had been found with about half the testing done.

Lying in the opposite direction from the region where the disease is endemic, the Rocky Mountains had been considered a natural barrier to its westward spread. But in late March and early April, Colorado's Division of Wildlife found two infected mule deer west of the mountains.

Although the deer were wild, they were within the confines of a fence erected in July

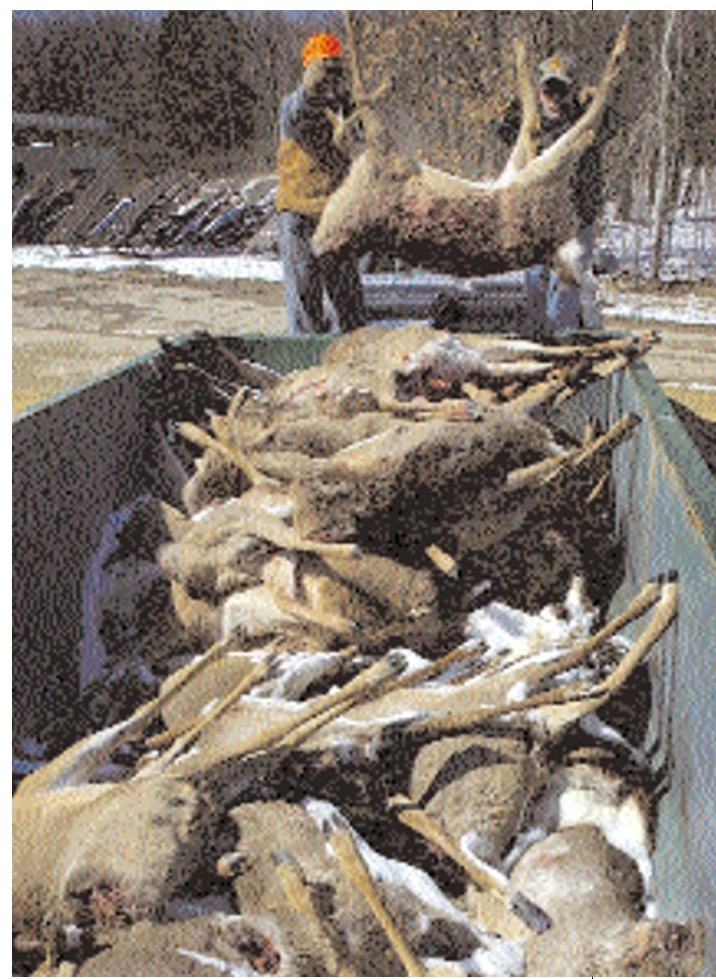

The recent discovery of chronic wasting disease in Wisconsin deer has prompted a major cull.

around a 1,500-acre ranch. Farm-raised elk brought to the ranch in August are a possible source of infection, although that would require a surprisingly rapid transmission, says Todd Malmsbury, chief spokesman for the division. Tests now under way on the elk

\section{Smithsonian rocked by high-level departure}

\section{Josette Chen}

Unease among researchers at the

Smithsonian Institution in Washington DC, the world's largest museum complex, deepened last week with the announcement that Dennis O'Conner, its undersecretary for science, will be departing.

O'Conner, who is also the acting director of the National Museum of Natural History, will become vice-president of research at the University of Maryland at College Park.

The departure adds to the atmosphere of turmoil at the museum complex, which has endured a bitter and public struggle between its cash-starved scientists and its secretary, Larry Small.
A science commission, chaired by Jeremy Sabloff, director of the University of Pennsylvania Museum of Archaeology and Anthropology in Philadelphia, was formed last year to advise on the restructuring of research at the Smithsonian, and will issue recommendations this autumn.

O'Conner says that he does not think his exit will leave the Smithsonian's research in the lurch. He says his decision is not a vote of no confidence in Small, but rather "a statement about College Park and the remarkable opportunity there".

However, Paul Forman, a curator for physics at the National Museum of American History, has branded the latest departure "a clear indication of the ruination of the institution that the secretary is pursuing".

Small himself was travelling and unavailable for comment. But a member of the Smithsonian's governing board of regents says that Small retains the board's confidence. "He has done the job the regents set out for him," says Manuel Ibanez, a biologist and former president of Texas A\&M University-Kingsville.

Ira Rubinoff, director of the Smithsonian Tropical Research Institute in Panama, has been proposed as a possible successor to O'Conner. But Rubinoff has said he would not take the job on an acting basis, and may be considered too close to retirement to be offered it permanently. 